\title{
Charles Frederick Hartt e a institucionalização das ciências naturais no Brasil
}

\author{
Charles Frederick. Hartt and the \\ institutionalization of the natural \\ sciences in Brazil
}

\author{
Nelson Sanjad \\ Museu Paraense Emílio Goeldi/MCT \\ nsanjad@museu-goeldi.br
}

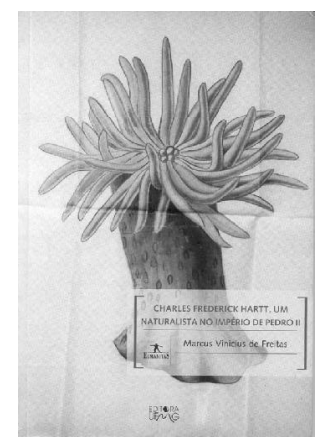

Marcus Vinicius de Freitas

Charles Frederick Hartt, um naturalista no Império de D. Pedro II Belo Horizonte, UFMG, 2002, 282p.

Marcus Vinicius de Freitas

Hartt: expedições pelo Brasil imperial (1865-1878), São Paulo, Metalivros, 2001, 250p.
Tos últimos anos, Charles Frederick Hartt (1840-1878) tem aparecido 1 com alguma freqüência em estudos sobre a institucionalização das ciências naturais no Brasil. Um dos nomes a se firmar na divulgação e análise da obra do naturalista canadense é o de Marcus Vinicius de Freitas, que publicou recentemente dois livros sobre o assunto. Frutos da pesquisa efetuada nos Estados Unidos durante o curso de doutorado, os livros também têm em comum o fato de serem belíssimas edições. O primeiro apareceu em 2001, um álbum bilíngüe (português/inglês) intitulado Hartt: expedições pelo Brasil imperial (1865-1878). O segundo foi lançado em 2002, uma versão de sua própria tese, Charles Frederick Hartt, um naturalista no Império de D. Pedro II.

O primeiro lançamento traz a iconografia e a documentação reunidas pelo autor nas visitas que fez a diferentes instituições norte-americanas, incluindo as Universidades de Cornell e Harvard, detentoras da maior parte dos papéis e coleções de Hartt. Juntamente com a iconografia, Marcus Vinicius apresenta alguns textos sobre as cinco viagens que Hartt fez pelo Brasil como membro da Expedição Thayer (1865-1866), de maneira independente (1867), nas Expedições Morgan (1870 e 1871) e na Comissão Geológica do Império (1875-1878).

Nos seis capítulos do livro, Marcus Vinicius destaca alguns pontos que considera relevantes na vida de Hartt, como o seu ingresso, em 1862, no Museu de Zoologia Comparada, em Harvard, recém-criado por Louis Agassiz. Ali Hartt completou sua formação acadêmica, alinhando-se à posição criacionista de seu professor. Sua permanência no museu permitiu-lhe participar, em 1865, da expedição que Agassiz organizou ao Brasil (Expedição Thayer), quando julgava poder encontrar indícios de sua teoria catastrofista e munição contra o evolucionismo de Darwin.

Entre o planejamento e a partida da expedição, Marcus Vinicius chama a atenção para um grupo de intelectuais norte-americanos que intermediou a relação entre Agassiz e dom Pedro II, em que destacam-se o reverendo James Cooley Fletcher, o poeta Longfellow e o pintor Martin Johnson Heade. Por meio de intensa troca de missivas e favores, os três seriam fundamentais para a aproximação entre Agassiz e o imperador brasileiro, cuja conseqüência maior seria o total apoio que o monarca concedeu ao naturalista e seus pupilos. Particularmente interessante no livro de Marcus Vinicius é a série 
de óleos pintados por Heade no Brasil retratando beija-flores, orquídeas e outras plantas.

Na sua primeira viagem ao Brasil, Hartt fez parte de um seleto grupo de naturalistas e curiosos, como Elisabeth Agassiz, esposa do líder da experdição e principal autora do relato da viagem, e o desenhista Jacques Burkhardt. Marcus Vinicius dedica algumas páginas para comentar a recepção que o grupo teve no país, a organização das atividades de pesquisa, o percurso pelo interior e a participação de Elisabeth, Hartt e Burkhardt. Digna de nota é a iconografia publicada sobre a viagem, boa parte dela vindo a público pela primeira vez. São inúmeras aquarelas de Burkhardt retratando peixes, paisagens e povoados; óleos de Hartt; desenhos e caricaturas de William James; fotografia de Marc Ferrez; fac-símiles de documentos; e gravuras elaboradas para o relato de viagem do casal Agassiz ( A journey in Brazil: 1865-1866) e para o livro de Hartt (Geology and physical geography of Brazil).

No capítulo seguinte, Hartt reaparece nos Estados Unidos, tentando encaminhar-se na carreira acadêmica a partir da experiência, das coleções e das informações adquiridas no Brasil. Levanta fundos para uma nova viagem, desta vez solitária, o que consegue realizar entre junho e setembro de 1867. Ao analisar os textos que resultaram dessa viagem, Marcus Vinicius demonstra o diálogo de Hartt com a literatura romântica brasileira, sinalizando que não apenas a carreira do naturalista foi construída com base nas suas viagens a um país tropical, como também sua própria obra é devedora das tradições culturais brasileiras.

O capítulo prossegue com o retorno do naturalista aos Estados Unidos, sua indicação para a cadeira de geologia da Universidade de Cornell e a organização de sua obra capital, Geology and physical geography of Brazil, publicada em 1870. Nesta obra, acrescida de suas próprias observações, Hartt faz uma síntese de vários textos escritos sobre a natureza brasileira, desde a carta de Pero Vaz de Caminha até livros de autores que lhe eram contemporâneos. Segundo Marcus Vinicius, isso faria de Geology and physical geography... um 'lugar de convergência, de distintas tradições provenientes da história natural, da história e da literatura. Hartt seria, portanto, um autor de transição entre o 'tipo romântico' — que se expõe e guia o leitor como em uma viagem, que faz da natureza o reflexo de seus sentimentos - e o cientista especializado, ausente da narrativa e disciplinado no olhar.

Para Marcus Vinicius o livro de Hartt foi, de fato, um 'passaporte' para a consolidação de sua carreira como geólogo e para suas futuras viagens ao Brasil. A partir do capítulo sobre as Expedições Morgan, o autor deixa patente essa idéia. Na primeira expedição, em 1870, Hartt chefiou nove alunos e um botânico. Rumou para o vale amazônico, onde pôde reavaliar a teoria de Agassiz e se dedicar à etnografia, lingüística indígena e arqueologia. O sucesso científico e pedagógico dessa expedição permitiu ao naturalista obter um novo patrocínio, partindo novamente para a Amazônia, para outra temporada de coletas, em 1871, acompanhado apenas de Orville Derby, seu aluno dileto.

Como resultado dessas viagens, o naturalista publicou alguns trabalhos em que revê sua posição original sobre a origem glacial dos terrenos amazônicos e refuta a teoria de Agassiz. Para Marcus Vinicius este pode ser considerado um marco na obra de Hartt e a abertura de um novo ciclo de 
trabalho na vida do naturalista, no qual, ao mesmo tempo em que se alinha às correntes evolucionistas, procura aproximar-se das instituições científicas brasileiras. Vale ressaltar a publicação, neste capítulo, dos painéis pintados a óleo por Hartt, retratando mapas, paisagens, espécimes animais e vegetais, objetos arqueológicos e cenas do cotidiano. Eles revelam, segundo Marcus Vinicius, não apenas os dotes artísticos do naturalista, como também suas preocupações pedagógicas ao produzir um 'museu de variedades' sobre o mundo tropical.

No capítulo sobre a Comissão Geológica do Império, Marcus Vinicius ratifica uma recente pesquisa, segundo a qual a idéia original da comissão partiu do próprio Hartt. Portanto, pode-se dizer, com o autor, que o naturalista, ao lançar mão de seu prestígio, de suas relações pessoais e de um apurado senso de oportunidade, soube inserir-se no sistema de patronagem característico do Império brasileiro. Em 1875, a comissão seria criada com sete integrantes, incluindo o fotógrafo Marc Ferrez. Boa parte do território brasileiro foi percorrido pelo grupo, conjuntamente ou em equipes menores, realizando exaustivas coletas e levantamentos fotográficos. Alguns exemplares dessas fotografias ilustram o capítulo, juntamente com uma pequena biografia do fotógrafo escrita por Sérgio Burgi.

A dissolução da comissão, em 1878, é assunto tão controverso quanto sua criação. Além dos fatos já divulgados na historiografia, como o desencontro de expectativas geradas entre os membros da comissão e o governo, Marcus Vinicius chama a atenção para ingredientes de ordem política. Em primeiro lugar, a coincidência entre a falta de apoio à comissão verificada a partir de 1877 e o longo período de ausência de dom Pedro II, protetor de Hartt e maior fiador dos seus trabalhos, em viagem aos Estados Unidos e Europa. Em segundo lugar, a inclusão da comissão no jogo político que resultou da troca do gabinete ministerial no início de 1878, independentemente das promessas e interesses pessoais do imperador. Segundo Marcus Vinicius, não fosse a morte de Hartt, ocorrida três meses depois da dissolução do grupo, a Comissão Geológica certamente teria sobrevivido, mesmo que reduzida ou reformulada.

No último capítulo do livro, o autor trata do legado de Hartt no Museu Nacional do Rio de Janeiro. Segundo Marcus Vinicius, a história dessa instituição cruza-se em diversos momentos com a vida de Hartt, desde que foi contratado como naturalista-viajante do museu, por volta de 1874. Em seguida, Hartt assumiu a Seção de Geologia, após a reforma institucional de 1876, acumulando-a com a direção da Comissão Geológica por dez meses. Ali, reorganizou as coleções e preparou a mostra mineralógica brasileira apresentada na Exposição Universal de Filadélfia. Com o fim da Comissão Geológica, o espólio de Hartt foi incorporado ao museu, que, por sua vez, homenageou o naturalista durante a Exposição Antropológica Brasileira realizada em 1882. Para Marcus Vinicius, portanto, a memória do naturalista foi construída juntamente com a memória da instituição a que se ligara no final da vida. Nesse sentido, parece ter sido intenção do autor alimentar esse jogo memorialístico ao incluir no livro um texto sobre uma coleção de invertebrados fósseis feita por Hartt e pertencente ao Museu Nacional, de autoria de Vera Maria Fonseca.

O segundo livro de Marcus Vinicius, Charles Frederick Hartt, um naturalista no Império de D. Pedro II, é, como já mencionado, a própria 
tese do autor. Sua estrutura difere do anterior, pois o autor, preocupado em trazer à luz a produção escrita de Hartt e em situá-la na sociedade brasileira da segunda metade do século XIX, organizou os capítulos em grandes temas, reveladores dos interesses e do 'percurso intelectual' de Hartt. Segundo Marcus Vinicius, os quatro temas centrais seriam: o relato de viagem como narrativa estruturante do pensamento científico de Hartt, o que o colocaria numa posição transitória entre o cientista romântico e o cientista especializado; a produção iconográfica de Hartt e sua relação com o paisagismo romântico; a antropologia como objeto de interesse do naturalista; e a atuação de Hartt nas instituições científicas brasileiras. Todos os temas, de uma maneira resumida e com outra organização, também foram abordados no primeiro livro, motivo pelo qual vamos nos limitar, doravante, à discussão de alguns pontos teóricos presentes na tese de Marcus Vinicius.

O autor disserta, no primeiro capítulo, sobre o papel do movimento romântico na construção de uma imagem da nação brasileira, processo agenciado pelo próprio imperador Pedro II. O discurso dos naturalistas, segundo o autor, também participa da construção de um conceito de nação, uma vez que a natureza aparece aí como elemento constitutivo do território. É nesse quadro, portanto, que Marcus Vinicius insere seu personagem, partindo do princípio de que os intelectuais encontraram um lugar privilegiado no Império de dom Pedro II e que as ciências naturais, ao serem incentivadas pelo governo, cumpriam a missão de reinventar o 'mito do paraíso tropical'.

No segundo capítulo, Marcus Vinicius chama a atenção para a formação romântica de Hartt, principalmente para a influência que Agassiz exerceria sobre seu aluno. Nesse sentido, situa a obra de Hartt na transição de uma "visão romântica das ciências naturais", definida como teológica e finalista, e uma "visão racional e desencantada da natureza", que se afirmava mundo afora por meio do darwinismo (p. 38). É por este viés que, nos capítulos seguintes, Marcus Vinicius analisa a obra do naturalista em suas múltiplas facetas, dos trabalhos arqueológicos aos estudos geológicos, de suas atividades como pintor e escritor aos afazeres acadêmicos. Segundo o autor, "as várias vertentes de sua visada sobre o Brasil só podem ser realmente compreendidas quando percebemos que elas formam um todo coeso" (p. 181). Tal perspectiva permitiria encontrar na obra do naturalista não apenas as características gerais de sua formação, os traços culturais de seu lugar de origem, mas também tomá-la como um "lugar de diálogo entre os saberes que circulavam na sociedade brasileira na segunda metade do século XIX" (idem).

Para Marcus Vinicius a formação romântica de Hartt encontrou eco no Brasil porque muitos intelectuais estavam aqui envolvidos com questões comuns às idéias de matriz germânica, particularmente com "a invenção da nacionalidade através da historiografia, através da língua e da literatura" ( $p$. 38). A sociedade brasileira, portanto, teria dado ao viajante Hartt o quadro ou a moldura para que pudesse desenvolver seus estudos, os quais, por sua vez, repercutiram fortemente no Brasil pelo viés com que foram escritos, conveniente ao tipo de discussão que se travava internamente. Para o autor, a obra de Hartt e a sociedade que percorreu influenciaram-se mutuamente. Aquela, pelo quadro dado por um determinado contexto; esta, pela mediação do olhar do viajante. Essa 'simbiose', se assim podemos chamar, teria permitido, inclusive, que o naturalista ganhasse reconhecimento no país e que fosse inserido no meio científico de maneira atuante. 
Nesse ponto, lembramos dos trabalhos de Maria Margaret Lopes (1994) e Silvia Figueirôa (1994), com quem Marcus Vinicius mantém estreito diálogo. No primeiro, a autora trata das contribuições de Hartt aos museus de história natural brasileiros. No segundo, Figueirôa analisa a Comissão Geológica do Império, concluindo que fora proposta pelo próprio naturalista e acolhida pelo governo para desempenhar determinados fins. O descompasso entre os interesses científicos do proponente e as expectativas econômicas do governo teriam, para Figueirôa, levado a Comissão a ser extinta prematuramente. Vemos, portanto, que, para os três autores, guardadas as diferenças de cada trabalho, a relação entre o viajante e a sociedade era uma via de mão dupla. Se, por um lado, ele buscou na sociedade os elementos (coleções, informações etc.) para a construção de sua carreira no seu país de origem, por outro também procurou tomar conhecimento das idéias e discussões em voga na sociedade e até mesmo se associar a diferentes espaços institucionais para melhor desempenhar seu trabalho.

Por mais que consideremos a década de 1870 como o marco do início de um novo tipo de viagem, com interesses cada vez mais especializados e influenciados pelo darwinismo - como defende Marcus Vinicius - , ou com naturalistas cada vez mais articulados com a sociedade brasileira como defende Margaret Lopes —, podemos considerar a abordagem desses autores bastante promissora se aplicada a viajantes de épocas mais remotas. Esse procedimento implicaria necessariamente um olhar sobre as dinâmicas locais, sobre a recepção e interação desses visitantes com a sociedade local, enfim, sobre aspectos até agora muito pouco considerados pela historiografia dos viajantes. Como, por exemplo, as redes sociais e relações científicas, quase sempre omitidas dos estudos cujos vetores principais sejam a relação metrópole-colônia, a narrativa de viagem ou as contribuições para esta ou aquela disciplina científica.

Há, contudo, algumas divergências entre os autores. Ao privilegiar no seu trabalho a maneira como a sociedade internaliza determinados valores que acabam interferindo na criação e no funcionamento das instituições científicas, Marcus Vinicius chama a atenção para um aspecto importante: "... o fato de que a institucionalização das ciências no Brasil do século XIX parece passar pela mediação desse olhar dos viajantes, o que aliás ambas as autoras acabam por reconhecer, apesar de não avançarem tal proposição" (p. 37). Segundo Marcus Vinicius, a "inserção cultural do discurso das ciências, o peso da palavra e do olhar dos viajantes - em sua relação com os cientistas locais - constitui uma baliza definidora e deve fazer parte do campo da análise" (idem).

Posto isso, o autor segue para o que constitui de fato o seu ponto central: a maior parte dos viajantes que estiveram no Brasil possuíam uma 'visão romântica' das ciências naturais, gerando - ao interagirem com grupos sociais que buscavam tornar a ciência uma prática regular e eficiente uma situação contraditória. Ou seja, ao mesmo tempo que os viajantes românticos influenciaram e aceleraram o processo de institucionalização das ciências, o fizeram em descompasso com a mais avançada ciência do momento, entendida pelo autor como o darwinismo. Segundo Marcus Vinicius, houve no século XIX "a sobreposição, de fora para dentro, de um certo discurso científico já defasado na origem. Ou seja, trava-se no Brasil uma luta em grande parte alheia a esse país: a luta entre o idealismo de um 
Agassiz e o empirismo racional de um Darwin". Se devidamente considerado, esse processo, segundo o autor, "pode jogar luz sobre as dificuldades enfrentadas pelos cientistas naquele mesmo movimento de institucionalização" (p. 39).

Como a polêmica diz respeito diretamente a toda uma vertente de estudos históricos em desenvolvimento no Brasil, alguns comentários merecem ser feitos. Em primeiro lugar, ressaltemos os marcos teóricos diferenciados entre os autores mencionados, que certamente justificam as escolhas individuais e orientam o foco da análise. Nesse sentido, Margaret Lopes e Silvia Figueirôa preocuparam-se em esmiuçar o funcionamento das instituições científicas e também com a construção de campos científicos, de acordo com um marco interpretativo que valoriza as instituições como pontos centrais da expansão da cultura científica no Ocidente.

Marcus Vinicius, por sua vez, faz uma análise alternativa ao marco institucional, aproximando-se dos estudos culturais norte-americanos, cujo nome mais conhecido no Brasil é o de Mary Louise Pratt. Portanto, ao dialogar com a historiografia das ciências naturais no Brasil, o autor arrisca-se em campos teóricos distintos para colocar o tema dos viajantes em uma perspectiva incomum à que podemos encontrar na vasta bibliografia brasileira sobre o assunto, caracterizada sobretudo pelos estudos de narrativas e inventários de expedições que percorreram o território.

Em segundo lugar, Marcus Vinicius pressupõe que a passagem do criacionismo para o darwinismo constituiu um avanço científico (em vez de uma substituição de paradigmas ou uma controvérsia científica). Daí considerar o primeiro como algo ‘defasado' e o segundo, como a representação científica do progresso. Esta idéia é questionável em vários aspectos, principalmente no fato de que a história da ciência — se for entendida como história social do conhecimento ou da cultura — não tem como presumir o que seja 'atraso' e 'progresso'.

No caso específico do problema levantado por Marcus Vinicius, há vozes dissonantes, que não consideram o criacionismo uma teoria 'defasada' até a década de 1870 e que ressaltam que alguns conceitos centrais para Darwin, como o transformismo de Lamarck e as teorias sobre a extinção de espécies de Cuvier, estavam formulados desde o início do século XIX e conviveram — embora não pacificamente — com o criacionismo. Ou seja, após 1859 verificou-se um confronto entre uma nova teoria (darwiniana) e uma complexa tradição disciplinar que não pode ser reduzida ao bastião levantado por Agassiz. Somente quando o paradigma da evolução polarizou o debate, delineando-se com algum grau de consenso, seus adversários deram consistência aos argumentos contrários a ele. Desse momento em diante, poderse-ia falar de conflito entre paradigmas, entre criacionismo versus evolucionismo. No caso de Hartt, como demonstrou Marcus Vinicius, a 'conversão' ocorreu ainda em 1870-1871, quase que simultaneamente ao lançamento de seu 'livro criacionista', Geology and physical geography...

Devemos considerar, por fim, que o darwinismo não foi a única corrente evolucionista do século XIX, não esgotando, portanto, o que poderia ser considerado 'avançado' para a época. Recentemente, Regina Gualtieri (2001) demonstrou que as próprias instituições científicas brasileiras do século XIX, que em Marcus Vinicius aparecem sofrendo de um 'mal de origem', selecionaram e incorporaram teorias evolucionistas distintas. 
E também se adaptaram sucessivamente para dar conta das novas disciplinas científicas que surgiram no período, não sendo possível, de acordo com Gualtieri, qualificá-las de 'defasadas' ou 'alheias' aos debates da época.

A polêmica, contudo, não está encerrada. Ela apenas começou. Marcus Vinicius teve o mérito de alimentá-la com criatividade, principalmente no que se refere ao lugar do discurso científico no processo de formação da nacionalidade brasileira na segunda metade do século XIX. Podemos identificar ainda temas associados a ele e igualmente desenvolvidos por Marcus Vinicius, como a relação entre ciência e romantismo no Brasil e a iconografia como fonte e expressão do pensamento científico, indissociável, portanto, da escrita. Especificamente sobre os estudos harttianos, Marcus Vinicius destacou muito bem a ambigüidade ou duplicidade da obra do naturalista no que se refere à sua formação na matriz idealista e posterior passagem para o evolucionismo, assim como deu margem para que a produção antropológica de Hartt emergisse das páginas amareladas de antigos periódicos.

Mas o mais importante talvez seja o fato de o autor ter tratado a viagem científica em suas múltiplas dimensões, inserindo o viajante na sociedade brasileira e demonstrando que sua obra nasce também das relações sociais que aqui estabelece. Esse detalhe nada desprezível irá sem dúvida garantir aos livros de Marcus Vinicius um lugar de referência nos estudos sobre viagens e viajantes.

\section{REFERÊNCIAS BIBLIOGRÁFICAS}

Figueirôa, S. F. de M. Charles Frederic Hartt and the "Geological Commission of Brazil (1875-1877)"'. 1994 Earth Sciences History, 13(2):168-173.

Gualtieri, R. C. E.

Evolucionismo e ciência no Brasil. Museus, pesquisadores e instituições, 2001 1870-1915. Tese de doutoramento em história, Universidade de São Paulo, São Paulo. (mimeo.)

Lopes, M. M. C. F. Hartt's contribution to brazilian museums of natural history'. $1994 \quad$ Earth Sciences History, 13(2), pp. 174-9.

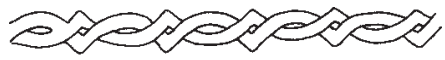

